\title{
Hemolytic uremic syndrome and IgA nephropathy in a child: Coincidence or not?
}

\author{
Serra Sürmeli-Döven ${ }^{1}$, Ali Delibaş ${ }^{1}$, İclal Gürses ${ }^{2}$, Uğur Raşit Kayacan ${ }^{3}$, \\ Banu Coşkun-Yılmaz ${ }^{4}$, Kaan Esen ${ }^{5}$ Emine Korkmaz ${ }^{6}$, Fatih Özaltın ${ }^{6}$ \\ Departments of ${ }^{1}$ Pediatric Nephrology, ${ }^{2}$ Pathology, ${ }^{3}$ Pediatrics, ${ }^{4}$ Histology and Embriology and ${ }^{5}$ Radiology, Mersin University \\ Faculty of Medicine, Mersin; Departments of 6 Pediatric Nephrology and Rheumatology, Nephrogenetics Laboratory, Hacettepe \\ University Faculty of Medicine, Ankara, Turkey. E-mail: serrasurmel@yahoo.com \\ Received: 13th March 2017, Revised: 10th April 2017, Accepted: 11th April 2017
}

SUMMARY: Sürmeli-Döven S, Delibaş A, Gürses İ, Kayacan UR, CoşkunYılmaz B, Esen K, Korkmaz E, Özaltın F. Hemolytic uremic syndrome and IgA nephropathy in a child: Coincidence or not? Turk J Pediatr 2018; 60: 81-85.

A previously healthy 18-month old boy, presenting with diarrhea, anemia, thrombocytopenia and acute renal failure was admitted to our hospital. Hemolytic uremic syndrome (HUS) was diagnosed with his clinical and laboratory findings. His stool was negative for Shiga toxin producing E. coli (STEC). During follow-up he developed respiratory distress, hypertrophic cardiomyopathy and seizure. His genetic tests for atypical HUS (aHUS) were negative. His clinical and histological findings indicated hemolytic uremic syndrome and immunglobulin A nephropathy (IgAN). The patient responded to steroid treatment and plasma exchange therapy with peritoneal dialysis. We discuss the probable connection between HUS and IgAN.

Key words: Hemolytic uremic syndrome, immunoglobulin A nephropathy, renal failure, glomerulonephritis, childhood.

Hemolytic-uremic syndrome (HUS) is one of the most common etiologies for acute kidney injury and an important cause of acquired chronic kidney disease in children. ${ }^{1}$ Classically HUS usually begins with gastrointestinal symptoms, followed by microangiopathic hemolytic anemia, thrombocytopenia and acute renal damage. On the other hand, secondary HUS is rare and is generally limited to adults. It is almost always associated with various conditions such as pregnancy, collagen disease, severe hypertension, cancer, or the use of certain drugs. But among those conditions, HUS associated with glomerular disease has rarely been reported and the relation between glomerular disease and HUS has been unknown. ${ }^{2}$ We present 18 -month old infant with clinical and laboratory findings of HUS whose kidney biopsy revealed immunglobulin A nephropathy (IGAN).

\section{Case Report}

A previously healthy 18-month old male infant was admitted to another hospital presenting with bloody diarrhea which started three days ago and oliguria. He was transferred to our hospital due to anemia and thrombocytopenia. Family history was negative for kidney disease. On admission, he was pale and had scrotal and pretibial edema. His neurological and cardiac examination was normal. Body temperature was $37.8^{\circ} \mathrm{C}$ and blood pressure was $105 / 68 \mathrm{mmHg}$. Laboratory investigations revealed anemia, thrombocytopenia and reticulocytosis. Direct coombs was negative. In peripheral blood smear there were fragmented erythrocytes. Other laboratory examinations yielded hyperuremia, creatinine increment, hyponatremia, LDH increment, hypocalcemia, hyperphosphatemia, hypertransaminemia, and metabolic acidosis (Table I). Occult blood in the stool was positive, serum complement 3 and 4 levels were within normal limits. Viral hepatitis markers (HbsAg, Anti-HCV, Anti-HIV Anti-HAV IgM) were negative. Stool culture for Shiga toxinproducing Eschericia coli (STEC), urine and blood 


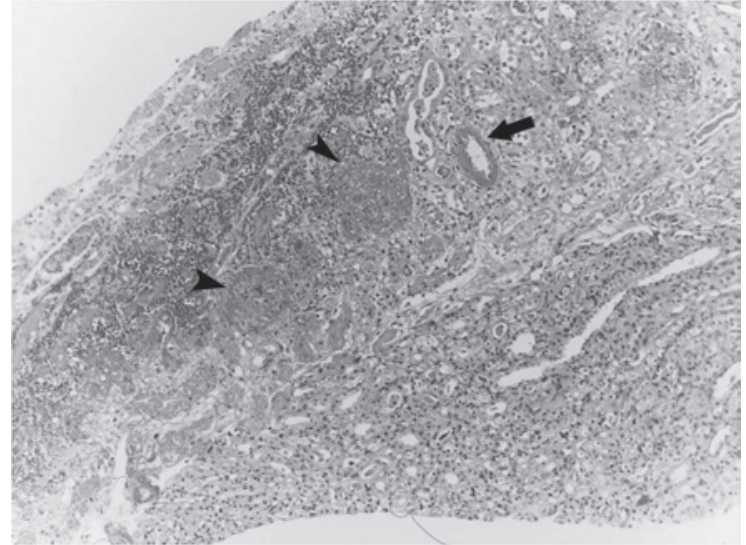

Fig. 1. Fibrinoid necrosis, thrombosis in glomeruli and arterioles (arrow head) and acute tubular necrosis (arrow) (H\&E, x200).

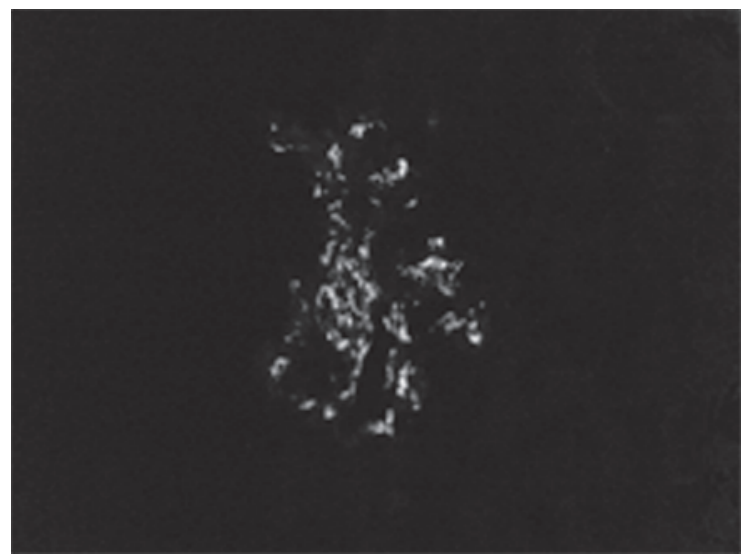

Fig. 2. Immunofluorescence staining shows diffuse IgA deposition in the mesangial matrix of glomeruli. (x400)

cultures were negative. He was diagnosed with HUS with the classic triad of microangiopathic hemolytic anemia, thrombocytopenia and acute renal failure. Plasma therapy was given twice daily. He was transfused with packed red cells. Because of oliguria and findings of hypervolemia, peritoneal dialysis was started. On $4^{\text {th }}$ day of the hospitalization he had a seizure and phenytoin therapy was started. He was treated with nifedipine to control his hypertension. During follow-up respiratory distress developed and mechanical ventilation was needed. Then he was transferred to the intensive care unit. Echocardiography showed hypertrophic cardiyomyopathy, therefore he was digitalized. A presumptive diagnosis of mithochondrial cytopathy was made, and coenzyme Q10 (5 mg/kg/day), carnitine (200 mg/day), and vitamin B complex were

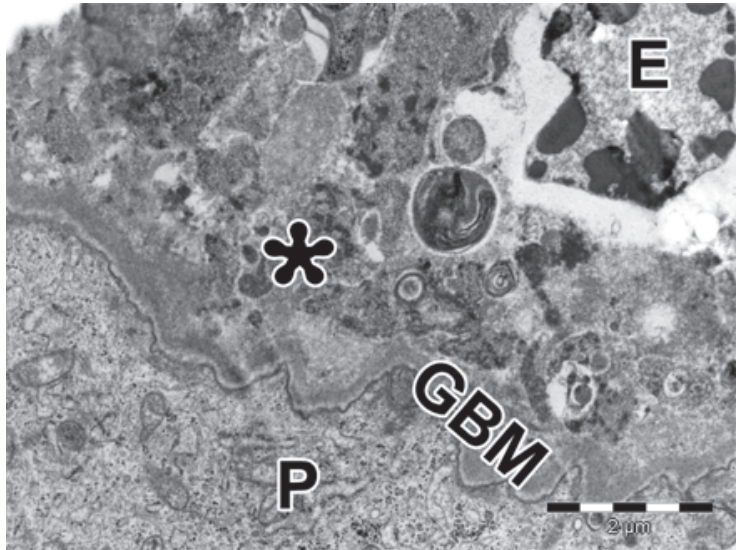

Fig. 3. Electron microscopy shows Glomerular capillary. Endothelial cell (E) degeneration, glomerülar basal membrane (GBM), podocyte $(\mathrm{P})$ and granular deposit (asterisk). X15000 (Uranyl acetate-Lead citrate)

initiated. Blood sample was taken for genetic analysis for mithocondrial cytopathy. For the genetic diagnosis of atypical HUS, mutations in complement factor $\mathrm{H}(\mathrm{CFH})$, complement factor B (CFB), complement factor I (CFI), complement $3\left(C_{3}\right)$, membrane cofactor protein $(M C P)$, and diacylglycerol kinase E (DGKE) were studied and all of them were found to be negative. ADAMTS-13 activity was normal. Slightly increased Anti-CFH antibody level was detected (Table II). Aminoacids in blood and urine tandem mass spectrometry and urine organic acids were within normal limits. Renal biopsy findings seemed consistent with the histological finding of HUS (Fig. 1). In addition, immunofluorescence showed immunglobulin A deposition in the mesangial matrix of glomeruli $(2+)$ (Fig. 2). Electron microscopy findings are shown in Figure 3. Based on these findings, the patient was diagnosed as thrombotic microangiopathy (TMA) accompanying IGAN. Plasma exchange was performed five times with one day intervals. Simultaneously pulse methylprednisolone was given for six days ( $15 \mathrm{mg} / \mathrm{kg} /$ day). After initiation of these therapies, creatinine level of the patient decreased from $3.5 \mathrm{mg} / \mathrm{dl}$ to $1.4 \mathrm{mg} / \mathrm{dl}$ and his urine output returned to normal level. On $22^{\text {nd }}$ day of hospitalization due to clinical improvement of the patient we managed to stop mechanical ventilation and peritoneal dialysis. Echocardiography returned to normal. Renal function improved in subsequent 10 days and the patient's general condition also remarkably improved. He was 
Table I. Laboratory Data on Admission.

\begin{tabular}{|c|c|c|}
\hline \multicolumn{2}{|l|}{ Urinary laboratory findings } & \multirow{2}{*}{$\begin{array}{l}\text { Normal values } \\
(-)\end{array}$} \\
\hline Protein & $(3+)$ & \\
\hline Glucose & $(-)$ & $(-)$ \\
\hline Occult blood & $(2+)$ & $(-)$ \\
\hline Sediment & Red blood ce & \\
\hline \multicolumn{3}{|l|}{ Hematologic laboratory findings } \\
\hline White blood cell count & $19.000 / \mathrm{mm}^{3}$ & $6-17 X 10^{3}$ \\
\hline Hemoglobin & $6.9 \mathrm{~g} / \mathrm{dl}$ & $11.3-14.1 \mathrm{~g} / \mathrm{dl}$ \\
\hline Hematocrit & $19.1 \%$ & $32-42 \%$ \\
\hline Platelet count & $70 \times 10^{3} / \mathrm{mm}^{3}$ & $6-17 \times 10^{3} / \mathrm{mm}^{3}$ \\
\hline Reticulocyte count & $4.8 \%$ & \\
\hline Blood smear & \multicolumn{2}{|c|}{$\begin{array}{l}\text { fragmanted eritrocytes, } 68 \% \text { neutrophils, } 18 \% \\
\text { lemphocytes, } 14 \% \text { monocytes. }\end{array}$} \\
\hline Activated partial thromboplastin time & $36.7 \mathrm{sec}$ & $6-17 \times 10^{3}$ \\
\hline Prothrombin time & $11.5 \mathrm{sec}$ & $6-17 \times 10^{3}$ \\
\hline Fibrinogen & $114 \mathrm{mg} / \mathrm{dl}$ & $175-400$ \\
\hline \multicolumn{3}{|l|}{ Blood chemical values } \\
\hline Urea & $142 \mathrm{mg} / \mathrm{dl}$ & $10.7-38.5 \mathrm{mg} / \mathrm{dl}$ \\
\hline Creatinine & $2.9 \mathrm{mg} / \mathrm{dl}$ & $<1.2 \mathrm{mg} / \mathrm{dl}$ \\
\hline Uric acid & $13.1 \mathrm{mg} / \mathrm{dl}$ & $<6.1 \mathrm{mg} / \mathrm{dl}$ \\
\hline Sodium & $129 \mathrm{mEq} / \mathrm{L}$ & $132-145 \mathrm{mEq} / \mathrm{L}$ \\
\hline Potassium & $5.3 \mathrm{mEq} / \mathrm{L}$ & $3.1-5.1 \mathrm{mEq} / \mathrm{L}$ \\
\hline Lactate dehydrogenase & $2633 \mathrm{U} / \mathrm{L}$ & $<850 \mathrm{U} / \mathrm{L}$ \\
\hline Creatinin kinase & $659 \mathrm{U} / \mathrm{L}$ & $<170 \mathrm{U} / \mathrm{L}$ \\
\hline Calcium & $6.9 \mathrm{mg} / \mathrm{dl}$ & $8.4-10.9 \mathrm{mg} / \mathrm{dl}$ \\
\hline Phosporus & $6.7 \mathrm{mg} / \mathrm{dl}$ & $4.5-5.5 \mathrm{mg} / \mathrm{dl}$ \\
\hline Alkaline phosphatase & $68 \mathrm{U} / \mathrm{L}$ & $<1107 \mathrm{U} / \mathrm{L}$ \\
\hline Alanine aminotransferase & $149 \mathrm{U} / \mathrm{L}$ & $<33 \mathrm{U} / \mathrm{L}$ \\
\hline Aspartate aminotransferase & $138 \mathrm{U} / \mathrm{L}$ & $<48 \mathrm{U} / \mathrm{L}$ \\
\hline Total bilirubin & $0.23 \mathrm{mg} / \mathrm{dl}$ & $0.3-1.2 \mathrm{mg} / \mathrm{dl}$ \\
\hline Bicarbonate & $13.7 \mathrm{mEq} / \mathrm{L}$ & $22-24 \mathrm{mEq} / \mathrm{L}$ \\
\hline
\end{tabular}

discharged on $35^{\text {th }}$ day of hospitalization. The total duration of his follow-up reached 21 months. He had no complaints and the current laboratory investigations revealed $\mathrm{Hgb}$ $12.6 \mathrm{~g} / \mathrm{dl}$, platelet $189000 / \mathrm{mm}^{3}$, urea $41 \mathrm{mg} /$ $\mathrm{dl}$, creatinine $0.52 \mathrm{mg} / \mathrm{dl}$. Urine protein was negative, without any pyuria and hematuria. He currently uses low dose prednisolone and enalapril. Informed consent was received from the family for publication.

\section{Discussion}

Our patient is a rare case with TMA accompanying IgAN in childhood. There are fifteen case reports of TMA with IgAN reported previously. 3,4 It is not exactly known whether IgAN is a preceding factor for developing TMA or simultaneous occurrence of these diseases is co-incidence. Since our patient was previously healthy with normal routine laboratory investigation we did not consider that he had IgAN. In our patient, HUS developed after acute diarrhea that made us think that it was a gastrointestinal infection. We consider that this infection could bring about IGAN, too. It was reported that microbial factors contribute to secondary IgAN by triggering the generation of pathogenic IgA and the deposition of IgA 
Table II. Genetic and Immunological Investigations.

\begin{tabular}{lll}
\hline Immunologic findings & & Normal values \\
\hline Immunglobulin G & $595 \mathrm{mg} / \mathrm{dl}$ & $604-1945 \mathrm{mg} / \mathrm{dl}$ \\
Immunglobulin A & $54 \mathrm{mg} / \mathrm{dl}$ & $33-107 \mathrm{mg} / \mathrm{dl}$ \\
Immunglobulin M & $65 \mathrm{mg} / \mathrm{dl}$ & $66-228 \mathrm{mg} / \mathrm{dl}$ \\
C reactive protein & $202 \mathrm{mg} / \mathrm{L}$ & $<5 \mathrm{mg} / \mathrm{L}$ \\
Complement 3 & $120 \mathrm{mg} / \mathrm{dl}$ & $79-152 \mathrm{mg} / \mathrm{dl}$ \\
Complement 4 & $34 \mathrm{mg} / \mathrm{dl}$ & $16-38 \mathrm{mg} / \mathrm{dl}$ \\
Plasma Complement factor H level & $2087.5 \mu \mathrm{g} / \mathrm{mL}$ & $400-800 \mu \mathrm{g} / \mathrm{mL}$ \\
Complement factor I mutation & $(-)$ & $(-)$ \\
Membrane cofactor protein mutation & $(-)$ & $(-)$ \\
$\mathrm{C}_{3}$ mutation & $(-)$ & $(-)$ \\
Diacylglycerol kinase e & $(-)$ & $(-)$ \\
ADAMTS-13 activity & $63.4 \%$ & \\
anti-CFH antibodies levels & $2.3 \mathrm{AU} / \mathrm{ml}$ & $<1 \mathrm{AU} / \mathrm{ml}$ \\
\hline
\end{tabular}

in the mesangium. ${ }^{5}$ As early as 1988 , in a study by Emencipator et al. ${ }^{6}$ IgAN had been successfully induced by mucosal immunity in an animal model. Thus, it is probable that with the excessive activation of intestinal mucosal immunity, serum IgA level increases significantly and deposits in the mesangial region. For this reason, HUS could theoretically overlap with IgAN in the setting of infection. ${ }^{7}$

In a study by Schmitt et al. ${ }^{8}$ it has been revealed that IgAN and microangiopathic hemolytic anemia are associated with the alterations of factor $\mathrm{H}$. It has been reported that an abnormal complement system may promote the development of $\operatorname{IgAN} .{ }^{9}$ Also, uncontrolled activation of the complement cascade is a significant etiological factor for atypical HUS (aHUS). We could not identify any genetic abnormality in $\mathrm{CFH}, \mathrm{CFB}, \mathrm{CFI}, \mathrm{C}_{3}$, $M C P$ and DGKE genes, ADAMTS-13 activity was normal and no significant anti-CFH antibody was detected. Thus, in our patient we did not think that uncontrolled activation of the complement cascade was a reason for developing both IgAN and HUS.

Since our patient showed atypic progress like developing hypertrophic cardiomyopathy, rhabdomyolysis and seizure, we consider that he could have had a mitochondrial disorder as an underlying factor of TMA. TMA associated with mitochondrial disorders has rarely been reported. A 2-year-old boy with recurrent HUS and rhabdomyolysis in whom succinate coenzym $\mathrm{Q}$ reductase (complex II) deficiency was diagnosed, has been reported. ${ }^{10}$ The authors explain the association of HUS and rhabdomyolysis as the effect of damage to endothelial cells of renal microvessels and other tissues such as muscle and pancreas. ${ }^{12}$ In a study by Andreoli et al. ${ }^{11}$ rhabdomyolysis was also suggested as an extrarenal finding of HUS. Genetic analyses for mithocondrial disorder were negative. Thus we exclude this diagnosis as a preceding factor.

Plasma exchange has been considered the mainstay of treatment in patients with aHUS. Efficacy of plasma exchange in patients with HUS and IgAN have also been reported anecdotally. ${ }^{12}$ Plasma exchange yielded renal and hematological remission and a favorable outcome in our patient.

In summary, we describe a patient with clinical and histological features of aHUS and IgAN who was successfully treated with plasma exchange and corticosteroids. In our patient, we believe that co-occurrence of these two distinct diseases might be secondary to an infection as the initiating stimulus rather than a coincidence. Although rare, association of HUS with other common primary glomerular diseases must always be kept in mind.

\section{REFERENCES}

1. Grisaru S. Management of hemolytic-uremic syndrome in children. Int J Nephrol Renovasc Dis 2014; 7: 231239. 
2. Sumiharu M. Sakai T. Okamoto Ni, et al. Hemolytic Uremic Syndrome Associated with Immunglobulin A Nephropathy: A Case Report and Review of Cases of Hemolytic Uremic Syndrome with Glomerular Disease. Intern Med J 1999; 38: 495-499.

3. Chang A, Kowalewska J, Smith KD, Nicosia RF, Alpers CE. A clinicopathologic study of thrombotic microangiopathy in the setting of IgA nephropathy. Clin Nephrol 2006; 66: 397-404.

4. Servais A, Frémeaux-Bacchi V, Lequintrec $M$, et al. Primary glomerulonephritis with isolated $\mathrm{C} 3$ deposits: a new entity which shares common genetic risk factors with haemolytic uraemic syndrome. J Med Genet 2007; 44: 193-199.

5. Pouria S, Barratt J. Secondary IgA nephropathy. Semin Nephrol 2008; 28: 27-37.

6. Emancipator SN. Experimental models of IgA nephropathy. Am J Kidney Dis 1988; 12: 415-419.

7. Wang R, Zhang Y, Li S, et al. Hemolytic uremic syndrome complicated with IgA nephropathy: a case report and literature review. Clin Nephrol 2015; 83: 36-40.
8. Schmitt R, Krmar RT, Kristoffersson A, Söderberg M, Karpman D. IgA nephropathy associated with a novel $\mathrm{N}$-terminal mutation in factor H. Eur J Pediatr 2011; 170: $107-110$.

9. Montinaro V, Gesualdo L, Ranieri E. Monno R, Grandaliano G, Schena FP. Renal cortical complement C3 gene expression in IgA nephropathy. J Am Soc Nephrol 1997; 8: 415-425.

10. Micheletti MV, Lavoratti G, Gasperini S, Domnati MA Pela I. Hemolytic uremic syndrome and rhabdomyolysis in a patient with succinate coenzyme $\mathrm{Q}$ reductase (complex II) deficiency. Clin Nephrol 2011; 76: 68-73.

11. Andreoli SP, Bergstein JM. Acute rhabdomyolysis associated with hemolytic-uremic syndrome. J Pediatr 1983; 103: 78-80.

12. Pipili C, Pantelias K, Papaioannou N, Paraskevakou H, Grapsa E. Hemolytic-uremic syndrome, malignant hypertension and IgA nephropathy: Successful treatment with plasma exchange therapy. Transfus Apher Sci 2012; 42: 155-158. 